\section{$\underset{\substack{\text { hommes } \\ \text { \& migrations }}}{ }$}

\section{Hommes \& migrations}

Revue française de référence sur les dynamiques

migratoires

$1320 \mid 2018$

Au prisme de la consommation

\title{
Italiennes : un film documentaire sur l'immigration au féminin
}

\section{Silvia Staderoli}

\section{OpenEdition \\ Journals}

Édition électronique

URL : http://journals.openedition.org/hommesmigrations/4074

DOI : 10.4000/hommesmigrations.4074

ISSN : 2262-3353

Éditeur

Musée national de l'histoire de l'immigration

Édition imprimée

Date de publication : 1 janvier 2018

Pagination : 136-138

ISBN : 978-2-919040-40-7

ISSN : $1142-852 X$

Référence électronique

Silvia Staderoli, «Italiennes : un film documentaire sur l'immigration au féminin », Hommes \& migrations [En ligne], 1320 | 2018, mis en ligne le 01 janvier 2018, consulté le 06 janvier 2021. URL : http:// journals.openedition.org/hommesmigrations/4074; DOI : https://doi.org/10.4000/ hommesmigrations.4074 


\section{MÉMOIRES}

\section{ITALIENNES}

\section{UN FILM DOCUMENTAIRE SUR L'IMMIGRATION AU FÉMININ}

Par SILVIA STADEROLI, réalisatrice.

$\mathrm{D}$ epuis que j'ai émigré en France, mon pays d'origine est devenu, au cours des années, un lieu imaginaire, figé dans ma mémoire, comme si l'image de « mon Italie à moi » pouvait se condenser en une seule photo prise le jour de mon départ. Mon italianité est depuis soumise aux fluctuations d'une mémoire que je m'obstine à ranimer jour après jour, et qui s'incarne dans les photos de famille que j'ai emmenées avec moi et exposées dans mon salon. Mes souvenirs sont aussi peuplés de sons du quotidien, de chansons, de voix de personnages familiers et habités par une langue, l'italien, quej'utilise souvent dans le cadre familial ou dans les conversations téléphoniques avec "l'autre côté des Alpes ».

Cette sensation de déracinement est accentuée par le fait d'être mère d'une enfant qui, dans son processus d'intégration, est progressivement devenue française. Que lui ai-je légué de mon italianité ? Que transmet-on de la culture d'origine une fois qu'on a émigré ?

J'ai ressenti la nécessité de partager cette question qui imprègne mon quotidien avec d'autres femmes, elles aussi issues de l'immigration italienne, ayant connu directement ou indirectement le déracinement. Elles vont témoigner dans un film documentaire choral qui va sonder deuxéléments fondamentaux, vecteurs de cette réflexion autour de la condition des émigrées : la mémoire et la transmission.
Transmission de la langue, mais aussi de tout ce qu'elles considèrent liés à "l'identité italienne ": une conception de la vie, un art culinaire, une vision de la famille, de la convivialité, un humour particulier ; mémoire d'une famille, d'un territoire, d'un contexte particulier, qui est elle-même rarement linéaire, mais au contraire fragmentée, éparse, parfois évanescente.

Au fil des mois, j'ai récolté leurs souvenirs et leurs photos de famille, écouté les histoires des différentes femmes que j'ai eu l'opportunité de rencontrer dans un atelier d'écriture documentaire de création partagée, mis en œuvre par Arcadi île-deFrance dans le cadre de Passeurs d'images.

\section{L'identité italienne en héritage}

Au cours de l'atelier, les femmes se sont questionnées, tantôt au travers de conversations intimes, tantôt par le biais d'échanges en groupe à l'extérieur et en l'occurrence dans l'espace urbain, sur leur rapport à leur italianité : se sentent-elles aussi fortement que moi en proie à la nécessité de préserver leurs racines culturelles et, dans certains cas, de "reconstruire " leur mémoire afin de la transmettre?

Il s'agissait de croiser les regards et les expériences particulières de ces femmes, leurs mémoires, leurs récits, croiser l'intime et l'historique à travers des 
archives privées et publiques, photos, sons, objets..., autant de traces et d'empreintes visuelles et sonores de la mémoire.

Issues de différentes générations, ces femmes ont émigré à des époques et des étapes différentes de leurvie, ou elles sont nées en France de parents ou de grands-parents italiens. Elles sont toutes mères d'enfants français et, pour cette raison, elles ressentent la nécessité de transmettre leur identité italienne. Leurs interrogations ne sont pas les mêmes. Celles qui sont nées en Italie se questionnent davantage sur la manière de préserver leur part italienne, de la maintenir vivace et de la perpétuer notamment à travers leurs enfants.

D'autres, nées en France, tentent surtout de retrouver dans leur présent l'essence d'un pays où elles n'ont jamais vécu en entreprenant des recherches généalogiques parfois poussées concernant leur origine, perdue dans les générations précédentes; un passé dont il ne reste que quelques photos ou une chanson qui a traversé le temps jusqu'à elles, pour subsister au creux de leur mémoire : perte des parents, séparation de la fratrie, déracinement, dissolution de la famille, rupture des liens avec la terre d'origine... Notre volonté provient pour nous toutes d'un double mouvement : s'efforcer de cultiver une mémoire familiale pour ensuite rendre possible sa transmission aux générations suivantes.

Si le recueil de ces traces mémorielles est une démarche individuelle, le désir de transmission est souvent influencé par un contexte social et historique qui valorise la quête des origines. Comme nous pouvons le lire dans différents ouvrages, le rapport à la culture italienne d'origine au sein des familles immigrées en France a, de fait, évolué durant les cinquante dernières années.

$\mathrm{Si}$, pour une première génération d'immigrés, l'intégration supposait une sorte de rejet, plus ou moins ostensible, de la culture italienne, permettant aux enfants et aux petits-enfants d'être "comme tout le monde ", donc des "Français à part entière ", la deuxième génération a hérité des conflits identitaires de leurs parents en gardant les stigmates de cette transmission manquée. C'est seulement à la troisième génération que l'on observe une quête parfois exacerbée de la culture d'origine qui s'exprime par des études universitaires axées sur la langue italienne, la fréquentation des cours d'adultes d'apprentissage de l'italien pour transmettre la langue à la génération suivante. Le statut de ce bagage culturel italien se pose, par conséquent, différemment : vécu autrefois comme une « honte ", il est désormais considéré comme une véritable richesse, sentiment partagé par une dernière vague d'expatriés diplômés et souvent polyglottes, arrivée en France depuis les années 1990.

\section{Mémoires féminines de l'Italie}

La particularité d'Italiennes réside aussi dans le choix de concentrer mon propos sur les mémoires d'immigration italienne au féminin.

Si les hommes apparaissent, dans les études spécialisées, comme vecteurs d'intégration, notamment par leurs engagements professionnels ou dans la sphère publique, le rôle des femmes dans l'histoire de l'immigration italienne a été largement minoré et peu étudié, celles-ci n'ayant pas - a priori - d'influence décisive dans la décision d'émigrer, ni dans le statut social et économique de la famille une fois installées dans le pays d'accueil. Comme l'écrivait la sociologue Mirjana Morokvasic, pionnière en France de la recherche sur les immigrantes, dans la revue L'année sociologique (1975) "Les études sociologiques ayant pour objet l'analyse de la situation des femmes migrantes sont pratiquement inexistantes en France. Les femmes migrantes ont été mentionnées et le sont encore, dans le cadre des travaux sur la famille, dans le chapitre sur les enfants, donc dans des domaines considérés "par nature" comme spécifiquement féminins. Dans la plupart des recherches sur l'immigration, les femmes sont en effet le plus souvent appréhendées pour leur statut d'épouse ou de mère au foyer, et toujours reliées à la figure du travailleur immigré." 


\section{MÉMOIRES}

Si elles ont autrefois été représentées dans la littérature spécialisée sous cet unique prisme de " gardienne de la mémoire", souvent en charge de recueillir les traces matérielles de l'histoire familiale, il faut aussi constater qu'aujourd'hui, trente ans après un premier état de la question par Mirjana Morokvasic, les études spécialisées ont commencé à prendre en compte l'émancipation des femmes immigrées, battant en brèche l'idée répandue selon laquelle elles auraient surtout accompagné les hommes dans
Si le recueil de ces traces

mémorielles est une démarche individuelle, le désir de transmission est souvent influencé par un contexte social et historique qui valorise la quête des origines. l'immigration, et que leur place se serait limitée essentiellement à la dimension domestique et maternelle.

Italiennes entend donc à la fois réhabiliter, dans le contexte tout particulier de l'immigration italienne, cette fonction de "passeuse ", qui légitime l'importance primordiale de la préservation de la culture d'origine, en y accolant toutefois une dimension supplémentaire, celle d'une émancipation par le travail et toute forme d'intégration sociale s'écartant forcément des assignations traditionnelles.

Même si les études sur le genre des années 1980 ont permis de repenser la position des femmes dans le contexte migratoire et comme j'ai pu le découvrir au cours des ateliers d'écriture, les discours sur les femmes et les discours des femmes sur elles-mêmes ont encore tendance à diverger : les représentations collectives ne correspondent pas toujours à celles que les individus ont d'eux-mêmes.

C'est précisément cet écart que le film propose d'explorer, en permettant à ces femmes de prendre enfin la parole et ainsi contribuer à les sortir de la double invisibilité - femmes et immigrées - dans laquelle la recherche les confinait et à leur rendre leur juste place dans l'histoire collective de la France.

\section{Bibliographie sélective}

- Mirjana Morokvasic, «L'immigration féminine en France : état de la question ", in L'année sociologique, vol. 26, 1975, pp. 563-575.

- Mirjana Morokvasic, « Femmes, genre, migrations et mobilités", in Revue européenne des migrations internationales, vol. 1, $\mathrm{n}^{\circ}$ 1, 2005.

- Michel Dreyfus, Pierre Milza, Un siècle d'immigration italienne en France, 1850-1950, Paris, CEDEl, 1987.

- Antonio Bechelloni, Michel Dreyfus, Pierre Milza, L'intégration italienne en France, un siècle de présence italienne dans trois régions françaises (1880-1980), Bruxelles, Complexe, 1995.

- Anne Muxel, Individu et mémoire familiale, Paris, Nathan, 1996.

- Marie-Claude Blanc-Chaléard, Les Italiens dans l'Est parisien: une histoire d'intégration (1880-1960), Rome, Publications de l'École française de Rome, 2000.

- Marie-Claude Blanc-Chaléard, Les Italiens en France depuis 1945, Rennes, Presse universitaire de Rennes, 2003.

- Claudie Le Bissonnais (dir.), Mémoire(s) plurielle(s), Paris, Arcadi/Creaphis, 2007.

- Linda Guerry (dir.), «Femmes et genre dans I'histoire de l'immigration ", in Genre \& Histoire, $n^{\circ}$ 5, 2009.

- Lina Bernabotto, Ces choses non dites et quifont leur chemin, Paris, L'Harmattan, 2011.

- Laure Taulières (dir.), «Italiens, 150 ans d'émigration en France et ailleurs », in RADICI, 2011.

- "Les femmes de l'immigration, XIXe-XXe siècles", in Migrance, $n^{\circ}$ 42, 2013.

- "Migrations, flux, frontières, numérique », in Projections, $n^{\circ}$ 35, 2014.

- Exposition «Migrations au féminin, un siècle d'histoire en France ", Association Génériques, 2015. 